\title{
Unique Screener of Reading Fluency and Comprehension for Adolescents and Adults
}

\author{
Sherry Mee Bell, Kelli Caldwell Miller, Ralph Steve McCallum, Michael Hopkins, \\ Angela Hilton-Prillhart \\ University of Tennessee, Knoxville, USA \\ Email: \{sbell1, kcaldwe9, mccallum, mhopkin7, amounger\}@utk.edu
}

Received October $5^{\text {th }}, 2011$; revised November $12^{\text {th }}, 2011$; accepted December $13^{\text {th }}, 2011$

\begin{abstract}
Because there are few brief reading fluency screeners available for older adolescents and adults we developed one, then investigated its psychometric properties, obtained for 161 college students. Two experimental versions of this unique, silent, group-administered screener of reading fluency and comprehension require adolescents and adults either to read and identify ideas or words (i.e., word chaining) within connected text of increasing difficulty. Both instruments and the Nelson-Denny Reading Test (Brown, Fishco, \& Hanna, 1993) were administered in counterbalanced order. Results indicate moderately strong relationships ( $r$ values ranged from .52 to .63 ) between both versions of the screener and Nelson-Denny comprehension and rate scores. These data provide preliminary evidence of validity for these screeners for this population. The format requiring examinees to identify ideas produced slightly higher correlations with Nelson-Denny comprehension scores than did the word chain format. Both may be useful because they can be created from existing curriculum materials and are efficient (i.e., group administered) and quick (requiring only 5 minutes).
\end{abstract}

Keywords: Reading; Assessment; Adolescent; Adult

\section{Introduction}

The National Reading Panel (NRP) identified reading comprehension as the ultimate goal of reading (National Institute of Child Health and Human Development, NICHD, 2000). However, because reading comprehension is difficult and time consuming to measure, researchers and educators often rely on measures of reading fluency to make educational decisions, in part because fluency is a precursor (and bridge) to reading comprehension as well as a powerful predictor (NICHD, 2000; Rasinski \& Padak, 2004; Samuels, 2007). Given the relationship between fluency and comprehension, assessments that are influenced by comprehension but also sensitive to rate and accuracy are potentially valuable. The purpose of this study is to investigate the psychometric properties of a unique group-administered reading screener for adolescents and adults that requires examinees to identify ideas in connected text of increasing difficulty: the Fluency and Comprehension Screener: Adults and Adolescents Ideas (FACS:A Ideas; Bell \& McCallum, 2010). A secondary purpose is to evaluate the relationship between an established measure of reading comprehension and both the FACS: A Ideas format and an alternative format, which requires examinees to identify words in connected text (word chaining).

\section{Efficient Screening of Reading Fluency and Comprehension of Adolescents and Adults: A Brief Review}

Several fluency measures are currently available for use with children (e.g., DIBELS, Good, \& Kaminski, 2002; AIMSweb, 2007). However, these measures have been criticized because they emphasize speed of word reading over comprehension (Kuhn, Schwanenflugel, \& Meisinger, 2010; Samuels, 2007) and are time consuming to administer and score (Allington, 2009). To minimize time required for assessment, silent groupadministered measures of reading have been developed, for example, the Test of Silent Word Reading Fluency (TOSWRF; Mather, Hammill, Allen, \& Roberts, 2004) and the Test of Silent Contextual Reading Fluency (TOSCRF; Hammill, Wiederholt, \& Allen, 2006). Both assessments require students to mark between words, a word chaining technique, using unrelated words (TOSWRF) or connected text (TOSCRF). In a study of 52 students ages 9 to 15 years, Bell, McCallum, Richardson, Fuller and McCane (2007) found correlations of similar magnitude between the TOSWRF $(r=.30, p<.05)$ and TOSCRF $(r$ $=.32, p<.05)$ with a measure of reading comprehension. Further, they found that TOSCRF produced a higher correlation $(r$ $=.58$ ) with a measure of sight word recognition and a measure of orthography $(r=.41)$ than with comprehension $(r=.32)$. Though potentially useful as group screeners, these word chaining measures may be only modestly related to comprehension and they are not normed for adults; upper age limit for the TOSWRF is 17-11, for the TOSCRF, 18-11.

Other comprehensive achievement tests (e.g., Kaufman Tests of Educational Achievement-II, Kaufman, \& Kaufman, 2004: Woodcock Johnson-III, McGrew, \& Woodcock, 2001) include measures of reading fluency that are normed for adults, but many of these measures are individually administered and expensive. Still others are group-administered and brief, like the Nelson-Denny Reading Test (Brown, Fishco, \& Hanna, 1993) but have other problems (e.g., dated norms, a rate measure based on only one minute of silent reading).

Given the increase in students with learning disabilities in 
college settings (Trainin \& Swanson, 2005) and the large number of adolescents and adults who are not proficient readers of English, there is a need for accurate and quick screeners.

Estimates of adults in the U.S. who lack basic literacy skills range from 30 million (Kutner, Greenberg, \& Baer, 2005) to over 80 million (Albro, 2009). According to Wirt et al., 2002, reading deficiencies are the biggest challenge that underprepared students face in college; further, ACT reports that only $51 \%$ of high school graduates tested by ACT are prepared for freshman courses (ACT, 2006). In 2004, approximately $40 \%$ of freshmen entering U.S. year colleges were enrolled in at least one developmental reading course (U.S. Department of Education, 2004). Only $38 \%$ of high school seniors performed at or above the Proficient level in reading on the National Assessment of Educational Progress in 2009 (U.S. Department of Education, 2009). Given the large number of young adults who are underprepared in reading, a quick screener could provide useful information for adult educators (Ziegler, McCallum, \& Bell, 2007), instructors and personnel in developmental reading programs and in college and university disability service settings.

Because most currently available reading fluency measures are time-consuming, emphasize reading speed over comprehension, and are inappropriate for adults, a quick screening tool to gauge reading skills could be quite useful. Consequently, Authors (2010) developed the FACS:A to meet this need and in this manuscript report reliability and validity of the instrument.

\section{Method}

\section{Participants and Setting}

Data were collected from 161 college students (126 females [78.3\%] and 35 males [21.7\%]) enrolled in teacher education courses at a large public university in the southeastern United States. Participants ranged in age from 19 to 57 years (average age $=25.69$ years). Reported race of participants was: Caucasian (91.9\%), African American (3.7\%), Asian/Pacific Islander (1.2\%), Native American (0.6\%), and Other (0.6\%), with $1.9 \%$ not reported. All but two were native English speakers. Participants included seniors and first-year graduate students.

\section{Instruments}

Fluency and Comprehension Screener: Adults (FACS:A). Alternate response formats of FACS:A (Ideas and Words) were administered. The FACS:A Ideas uses a unique technique that requires slashing between words that end and begin a complete idea while the format of FACS:A Words requires slashing between words embedded in authentic text (i.e., word chaining, similar to the format of the TOSCRF). A complete idea is defined essentially as a sentence; to avoid ambiguity, we include dependent clauses but not compound sentences or independent clauses. Examinees must read carefully to determine where an idea ends or begins. In development each passage was read by three graduate students with assessment background; agreement on when ideas begin and end averaged 99\%. Brief practice passages are presented prior to the timed assessment. Each form includes the same six passages, alternating expository and narrative passages of increasing difficulty, ranging from 4.7 to 13.2 grade level (using the Flesch Kincaid readability formula from Microsoft Word). Though readability formulae vary and may not yield consistent results across formulae (Bell \& McCallum, 2008), the Flesch Kincaid is adequate for deter- mining an increasing difficulty level from passage to passage. The passages are written in lower case letters and without ending punctuation, and include varying numbers of sentences, each arranged to create a coherent, meaningful paragraph. Forms are identical except for spacing; for the Ideas version, spaces are only between words, e.g.,

the star shone brightly in the sky the sky was cloudless while for the FACS:A Words version, spaces within and between words are the same, e.g.,

$$
\text { the starshonebright } 1 \text { y }
$$

Both forms are timed; examinees are given four minutes to read and mark as many ideas (FACS: A Ideas) or words (FACS:A Words) as possible. Initial validity data for a pilot version of the FACS: A Ideas were obtained from a sample of 163 college students who also took the Nelson-Denny and the Modern Language Aptitude Test (MLAT; Carroll \& Sapon, 1959, 2002). The correlation coefficient between the pilot FACS:A Ideas and reading rate and comprehension from the Nelson-Denny were .39 and .50 , respectively; of note, the correlation with comprehension was higher than with rate. Further, though modest, correlations between the pilot FACS:A Ideas and the MLAT were significant and higher than correlations between the Nelson-Denny and the MLAT (.24 to .37 versus .05 to .30$)$ (Hopkins, Mounger, Kirk, \& McCallum, 2009). Test-retest data for the pilot version (over a two week period) indicated a correlation coefficient of .95 for a subsample of 27 participants. Inter-scorer reliability (95\%) for this version was also impressive across three raters (percentage agreement divided by percentage agreement plus percentage disagreement).

Because the pilot version of the FACS:A Ideas had a limited ceiling (the most difficult passage readability was 6.5 using Flesch Kincaid), additional passages of increasing difficulty were written and passages with readability lower than $4^{\text {th }}$ grade were eliminated. Further, because the novel technique (marking between ideas) is essentially untested, two forms of the FACS: A were created for this study. The score from FACS:A Words was determined by counting the total number of words read minus the errors made when slashing between words (e.g., extra misplaced slashes, omissions). Reliability and validity data on the word chaining "word" format is available (see Hammill, et al., 2006; Mather, et al., 2004; Miller-Guron, 1999).

Scores from FACS:A Ideas included the total words read, percent of ideas correct, and comprehension $\mathrm{x}$ rate. Total words read was calculated in a manner identical to that calculated for FACS:A Words. Percent correct was calculated by dividing the number of ideas correctly identified by the number of ideas the examinee attempted. Thus, percent correct is a measure of how accurately the individual identified ideas within the passages. Finally, comprehension $\mathrm{x}$ rate was calculated by multiplying the value obtained for percent correct (i.e., proportion) by the value obtained for total words read. Thus, the comprehension $\mathrm{x}$ rate score is a measure of fluency moderated by comprehension.

Nelson-Denny. Designed for students in high school and college, Nelson-Denny has two alternate forms and includes measures of vocabulary, comprehension, and reading rate (Brown, et al., 1993) though only comprehension and rate were assessed in the current study. Form G Comprehension subtest was administered; it consists of a series of seven expository passages followed by sets of multiple-choice comprehension questions. A Reading Rate measure is embedded in the Comprehension subtest, which has a 20 minute time limit. Reading 
Rate is determined by the approximate number of self-reported words read silently in one minute. Brown et al. reported alternate forms reliability for Reading Rate $(r=.68)$ and for Comprehension $(r=.81)$. Scale score norms for college students were used in the data analyses.

\section{Procedures}

Alternate response formats of FACS:A were administered in counterbalanced order, followed by the Comprehension subtest of the Nelson-Denny during two semesters in the same calendar year, spring and fall. Measures were administered in classes, according to scripted directions, by a special education professor and trained graduate students in school psychology and special education. The University's policies on rights of human subjects were followed.

\section{Results}

Participants' means and standard deviations of scores from the FACS:A and Nelson-Denny scores are presented in Table 1. Nelson-Denny population scale score means and standard deviations are set to 200 and 25 respectively for both rate and comprehension measures. Pearson product moment correlations were calculated between participants' scale scores on Nelson-Denny Comprehension and Reading Rate and their FACS: A Words and Ideas scores and are presented in Table 2. Be-cause the standard deviations of our sample for reading rate and comprehension were less than 25 (21.63 and 18.61, respec- tively), correlations were corrected for restriction in range. All relationships were significant except for the relationship between percent of ideas correct (FACS:A Ideas) and NelsonDenny Reading Rate. FACS:A Ideas significantly correlated with Nelson-Denny Reading Rate $(r=.58, p<.01)$ and Comprehension $(r=.63, p<.01)$. And, FACS:A Words significantly correlated with Nelson-Denny Reading Rate $(r=.56, p$ $<.01)$ and Nelson-Denny Comprehension $(r=.52, p<.01)$. In sum, both formats yielded moderate correlations with both Nelson-Denny rate and comprehension. Further, the Ideas assessment yielded slightly stronger correlations with both rate and comprehension. Because the relationship between FACS:A Ideas and FACS: A Words and reading comprehension is of primary focus, we tested the statistical significance of the difference between the two coefficients (.52 and .63). The magnitude of the difference is not significantly different, $z=-.03, p$ $>.05$.

\section{Discussion}

The current study extends research on a pilot version of a unique group reading screener; previous research revealed stronger correlations between this experimental method with the MLAT than between the Nelson-Denny and the MLAT in a college sample (Hopkins, et al., 2009). Current results indicate that both FACS:A Ideas and FACS:A Words yield moderate correlations with comprehension as measured by the NelsonDenny. Additionally, FACS:A Ideas yields slightly higher

Table 1.

Means and standard deviations of participants' scores on the Nelson-Denny reading testing (ND) and the fluency and comprehension screener: adults (FACS:A) $(\mathrm{n}=161)$.

\begin{tabular}{ccc}
\hline Reading Measure & $M$ & $S D$ \\
\hline ND Reading Rate Scale Score & 201.67 & 21.64 \\
ND Comprehension Scale Score & 225.64 & 18.61 \\
FACS:A Ideas Total Words Read & 562.52 & 139.15 \\
FACS:A Ideas Percent Correct (Proportion) & .89 & .10 \\
FACS:A Ideas Comprehension x Rate & 505.20 & 147.78 \\
FACS:A Words Total Words Read-Errors & 178.52 & 39.37 \\
\hline
\end{tabular}

\section{Table 2.}

Pearson product moment correlation coefficients representing relationships between Nelson-Denny reading test (ND) and fluency and comprehension screener: adults, (FACS:A) ideas (I) and words (W) versions.

\begin{tabular}{|c|c|c|c|c|c|}
\hline & $\begin{array}{c}\text { ND } \\
\text { Reading Rate }\end{array}$ & $\begin{array}{c}\text { ND } \\
\text { Comprehension }\end{array}$ & $\begin{array}{c}\text { FACS:A Ideas } \\
\text { Total Words Read }\end{array}$ & $\begin{array}{l}\text { FACS:A Ideas } \\
\text { Percent Correct }\end{array}$ & $\begin{array}{c}\text { FACS:A Ideas } \\
\text { Comprehension/Rate }\end{array}$ \\
\hline \multicolumn{6}{|l|}{ ND Reading Rate } \\
\hline ND Comprehension & $.35^{*}$ & & & & \\
\hline FACS:A Ideas Total Words Read & $.54 *(.59)$ & $.47 *(.58)$ & & & \\
\hline FACS:A Ideas Comprehension x Rate & $.50 *(.58)$ & $.52 *(.63)$ & $.95^{*}$ & $.61 *$ & \\
\hline FACS:A Words Words Read - Errors & $.51 *(.56)$ & $.41 *(.52)$ & $.52 *$ & $.34 *$ & $.54^{*}$ \\
\hline
\end{tabular}

Note: Values in parentheses are corrected for restriction in range; *Correlation is significant at the 0.01 level (2-tailed). 
correlations (though not significantly) than FACS:A Words. These results indicate that the unique format of FACS:A represents a promising method of screening rate and comprehension, particularly given that data reveal strong test-retest reliability of the FACS:A Ideas (.95), as compared to the authors' reported alternate form reliability of the Nelson Denny Reading rate (.68).

Results and implications are limited by sample characteristics-participants were teacher education students from one university. Further research should be conducted with a more diverse sample, i.e., adolescents and adult learners functioning across a wide range of literacy skills but especially at lower levels. Nonetheless, results provide preliminary support for the utility of this unique assessment format. The fact that participants in this sample identified a high percentage of ideas correct may have negatively impacted the correlation with comprehension. Extending the ceiling and/or using this technique with adolescents and adults with significant reading challenges may yield additional data to support its use with these populations.

In summary, this method appears to hold promise as an efficient screener to identify differences in how efficiently individuals read and comprehend connected text. Further, the technique can be used informally. That is, educators may simply import existing curriculum materials into the FACS:A Ideas format. Following the recommendation of Behrman (2000), educators could use content-specific text and use results to provide quick, rough estimates of their students' comprehension and fluency (words read per minute).

\section{REFERENCES}

ACT (2006). What the ACT reveals about college readiness in reading. Iowa City, IA: Author.

AIMSweb (n.d.) Retrieved January 8, 2007 from http://www.aimsweb.com

Albro, E. R. (2009). Funding for reading research: Grant competitions at the Institute of Education Sciences. Presentation to the National Reading Conference, Albuquerque, NM.

Allington, R. L. (2009). What really matters in fluency: Research-based practices across the curriculum. Boston: Pearson Education, Inc.

Bell, A. M., \& McCallum, R. S. (2010). Fluency and comprehension screener: Adults (FACS: A). Unpublished test. University of Tennessee.

Behrman, E. H. (2000). Developmental placement decisions: Contentspecific reading assessment. Journal of Developmental Education, 23, $12-14,16,18$

Bell, S. M., \& McCallum, R. S. (2008). Handbook of reading assessment. Boston: Allyn \& Bacon.

Bell, S. M. McCallum, R. S., Richardson, E., Fuller, E., \& McCane, S. (2007). Investigation of the psychometric attributes of the Test of Silent Contextual Reading Fluency. Assessment for Effective Intervention, 33, 39-46. doi:10.1177/15345084070330010501

Brown, J. A., Fishco, V. V., \& Hanna, G. (1993). Nelson-denny reading test: Manual for scoring and interpretation, forms $G \& H$. Rolling Meadows, IL: Riverside Publishing

Carroll, J. B., \& Sapon, S. (2002). Modern language aptitude test: Manual. N. Bethesda, MD: Second Language Testing, Inc.
Good, R. H., \& Kaminski, R. A. (2002). DIBELS oral reading fluency passages for first through third grades. (Technical report no. 10). Eugene, OR: University of Oregon.

Hammill, D. D., Wiederholt, J. L., \& Allen, E. A. (2006). TOSCRF: Test of silent contextual reading fluency: Examiner's manual. Austin, TX: Pro-Ed.

Hopkins, M. B., Mounger, A., Kirk, E. R., \& McCallum, R. S. (2009). Reading fluency: A brief ecological classroom assessment. Paper presented at the annual conference of the National Association of School Psychologists Conference, Boston, MA.

Kaufman, A. S., \& Kaufman, N. L. (2004). Kaufman tests of educational achievement (2nd ed.). Circle Pines, MN: American Guidance Service.

Kuhn, M. R., Schwanenflugel, P. J., \& Meisinger, E. B. (2010). Aligning theory and assessment of reading fluency: Automaticity, prosody, and definitions of fluency. Reading Research Quarterly, 45, 230-251. doi:10.1598/RRQ.45.2.4

Kutner, M., Greenberg, E., \& Baer, J. (2005). National Assessment of Adult Literacy (NAAL): A first look at the literacy of America's adults in the 21st Century (No. NCES 2006-470). Jessup, MD: National Center for Educational Statistics.

Mather, N., Hammill, D. D., Allen, E. A., \& Roberts, R. (2004) TOSWRF: Test of silent word reading fluency: Examiner's manual. Austin, TX: Pro-Ed.

McGrew, K., \& Woodcock, R. W. (2001). Woodcock-Johnson III technical manual. Itasca, IL: Riverside Publishing.

Miller-Guron, L. (1999). Word chains: A word reading test for all ages. Windsor, England: NFER-Nelson.

National Institute of Child Health and Human Development (2000). Report of the National Reading Panel: Teaching children to read (NIH Publication No. 00-4769). Washington DC: Government Printing Office.

Rasinski, T. V. \& Padak, N. (2004). Effective reading strategies: Teaching children who find reading difficult (3rd ed.). Columbus, OH: Pearson Merrill Prentice Hall.

Samuels, S. J. (2007). The DIBELS tests: Is speed of barking at print what we mean by reading fluency? Reading Research Quarterly, 42, 563-566.

Trainin, G., \& Swanson, H. L. (2005). Cognition, metacognition, and achievement of college students with learning disabilities. Learning Disability Quarterly, 28, 261-272. doi:10.2307/4126965

U.S. Department of Education, National Center for Education Statistics (2004). The condition of education 2004 (NCES 2004-077). Washington DC: U.S. Government Printing Office.

U.S. Department of Education. National Center for Education Statistics (2009). The nations' report card: Grade 12 reading and mathematics 2009 national and pilot state results. Washington DC: U.S. Government Printing Office.

National Center for Education Statistics (2004). The condition of education 2004 (NCES 2004-077). Washington DC: U.S. Government Printing Office.

Wirt, J., Choy, S., Gerald, D., Provasnik, S., Rooney, P., Watanabe, S., \& Tobin, R. (2002). The condition of education (DHHS Publication No. NCES 2002-025). Washington DC: U.S. Government Printing Office.

Ziegler, M. F., McCallum, R. S., \& Bell, S.M. (2007). Adult educators in the United States: Who are they and what do they know about teaching reading? In J. R. Kruidenier, \& S. M. Bell (Eds.), Perspectives on language and literacy (pp. 50-56). Baltimore, MD: International Dyslexia Association. 